\title{
How much of the effect of exercise and advice for subacute low back pain is mediated by depressive symptoms?
}

Citation for published version (APA):

Baadjou, V. A. E., Lee, H., Smeets, R. J. E. M., \& Kamper, S. J. (2019). How much of the effect of exercise and advice for subacute low back pain is mediated by depressive symptoms? Musculoskeletal science and practice, 44, [102055]. https://doi.org/10.1016/j.msksp.2019.102055

Document status and date:

Published: 01/12/2019

DOI:

10.1016/j.msksp.2019.102055

Document Version:

Publisher's PDF, also known as Version of record

\section{Document license:}

Taverne

Please check the document version of this publication:

- A submitted manuscript is the version of the article upon submission and before peer-review. There can be important differences between the submitted version and the official published version of record.

People interested in the research are advised to contact the author for the final version of the publication, or visit the DOI to the publisher's website.

- The final author version and the galley proof are versions of the publication after peer review.

- The final published version features the final layout of the paper including the volume, issue and page numbers.

Link to publication

\footnotetext{
General rights rights.

- You may freely distribute the URL identifying the publication in the public portal. please follow below link for the End User Agreement:

www.umlib.nl/taverne-license

Take down policy

If you believe that this document breaches copyright please contact us at:

repository@maastrichtuniversity.nl

providing details and we will investigate your claim.
}

Copyright and moral rights for the publications made accessible in the public portal are retained by the authors and/or other copyright owners and it is a condition of accessing publications that users recognise and abide by the legal requirements associated with these

- Users may download and print one copy of any publication from the public portal for the purpose of private study or research.

- You may not further distribute the material or use it for any profit-making activity or commercial gain

If the publication is distributed under the terms of Article $25 \mathrm{fa}$ of the Dutch Copyright Act, indicated by the "Taverne" license above, 
Original article

\title{
How much of the effect of exercise and advice for subacute low back pain is mediated by depressive symptoms? ${ }^{\text {ir }}$
}

\author{
Vera AE. Baadjou ${ }^{\mathrm{a}, \mathrm{b}, *, 1}$, Hopin Lee ${ }^{\mathrm{c}, \mathrm{d}, \mathrm{e}, \mathrm{f}}$, Rob JEM. Smeets ${ }^{\mathrm{b}, \mathrm{g}}$, Steven J. Kamper ${ }^{\mathrm{f}, \mathrm{h}}$ \\ ${ }^{a}$ Adelante Centre of Expertise in Rehabilitation and Audiology, Hoensbroek, the Netherlands \\ ${ }^{\mathrm{b}}$ Department of Rehabilitation Medicine, School for Public Health and Primary Care, Maastricht University, Maastricht, the Netherlands \\ ${ }^{\mathrm{c}}$ Centre for Statistics in Medicine, Nuffield Department of Orthopaedics Rheumatology and Musculoskeletal Sciences, University of Oxford, Oxford, UK \\ ${ }^{\mathrm{d}}$ School of Medicine and Public Health, The University of Newcastle, Newcastle, NSW, Australia \\ ${ }^{\mathrm{e}}$ Hunter Medical Research Institute, Newcastle, NSW, Australia \\ ${ }^{\mathrm{f}}$ Centre for Pain, Health and Lifestyle, Australia \\ ${ }^{\mathrm{g}}$ Libra Rehabilitation and Audiology, Eindhoven/Weert, the Netherlands \\ ${ }^{\mathrm{h}}$ Institute for Musculoskeletal Health, School of Public Health, University of Sydney, Sydney, Australia
}

\section{A B S T R A C T}

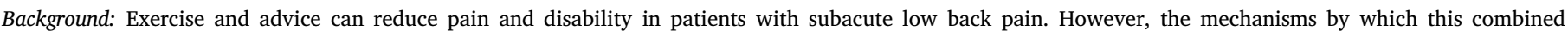

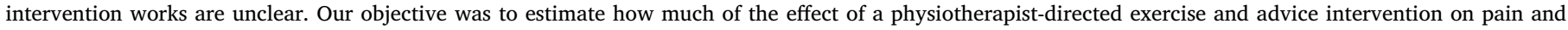
disability is mediated via changes in depressive symptoms.

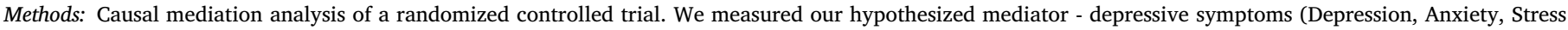

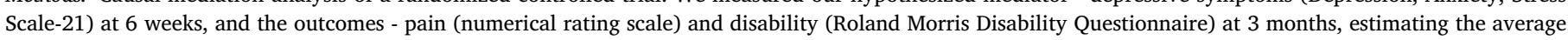

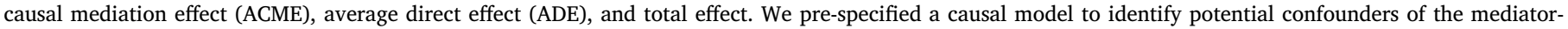
outcome effect and conducted sensitivity analyses to assess the robustness of the ACME under varying levels of unknown confounding.

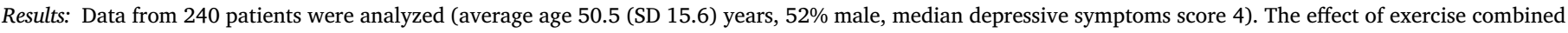

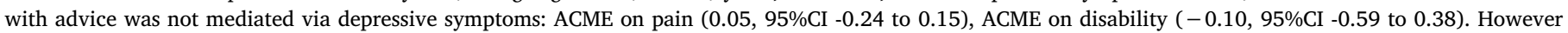
depressive symptoms were associated with pain (regression coefficient 0.06; SE 0.03)) and disability (regression coefficient 0.17; SE 0.05).)

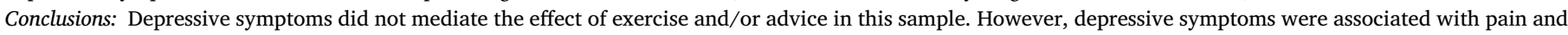
disability.

\section{Introduction}

Acute low back pain is common, but patients often experience rapid improvements in pain, disability and return to work within the first six weeks. During the subacute phase (six weeks - three months since onset), further improvement is apparent, resulting in $52 \%$ of patients being pain-free, and $71 \%$ being disability-free at three months after onset. However, if symptoms persist beyond the subacute period, patients typically do not experience much improvement. At one year after onset, $57 \%$ are pain-free (Pengel et al., 2003) and $75 \%$ are disabilityfree (Henschke et al., 2008). Back pain that progresses to chronicity can lead to profound individual and population burden (Hoy et al., 2014; Hartvigsen et al., 2018).
According to recent UK and US clinical practice guidelines for low back pain treatment (NICE guidelines 2016; Qaseem et al., 2017), a shift in thinking about the primary care management of low back pain is encouraged, with the focus on nonpharmacological treatment options and a stratified management approach guided by prognostic screening tools (NICE guidelines 2016). For example, all patients with nonspecific low back pain should be offered information about the nature of low back pain, reassurance about the likely low risk of serious underlying disease and advice on evidence-based self-management (Traeger et al., 2017). Patients with a high risk of poor outcome in the acute stage could benefit from specific nonpharmacologic treatments such as advice, exercise, or psychologically informed physiotherapy (Traeger et al., 2017; Foster et al., 2018). However, recommendations are based

\footnotetext{
The authors confirm that this manuscript is an original work that has not been previously published, nor is it currently under consideration for publication

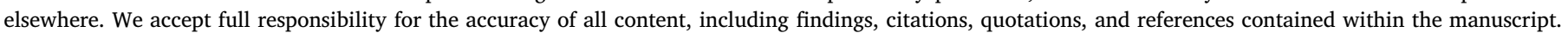

${ }^{*}$ Corresponding author. Vera Baadjou, Maastricht University, FHML, Department of Rehabilitation Medicine, Universiteitssingel 40, 6229 ER, Maastricht, the Netherlands.

E-mail address: vera.baadjou@maastrichtuniversity.nl (V.A. Baadjou).

${ }^{1}$ Postal Box 616, 6200 MD Maastricht, The Netherlands.
} 
on low to moderate quality of evidence with small effect sizes and working mechanisms of these treatments are unknown.

Pengel et al. (2007) conducted a factorial randomized, placebocontrolled trial to estimate the effect of physiotherapist-directed exercise and/or advice intervention to reduce pain and improve function in patients with subacute low back pain. The trial concluded that a clinically worthwhile improvement of pain at 6 weeks occurred in participants who received combined advice and exercise. Although the effectiveness of combined advice and exercise is clear, there is limited evidence for the underlying mechanisms of this intervention. That is, we do not understand how combined advice and exercise reduces pain and disability in patients with subacute low back pain. It is important to understand treatment mechanisms to guide the adaptation and implementation of this effective intervention (Lee et al., 2016; Lee and Lamb, 2017).

The presence of psychological factors, such as depressive symptoms, in people with subacute low back pain is associated with an increased risk of poor outcome (Hartvigsen et al., 2018; Pinheiro et al., 2016). This suggests that depressive symptoms could be an important treatment target for the prevention of chronic back pain. In other words, reducing depressive symptoms could lead to reduced pain and increased function in patients with subacute low back pain. The intervention tested by Pengel et al. (2007) included two strategies that could have an effect on depressive symptoms (exercise and advice). That is, exercise could reduce depressive symptoms via the modulation of neurobiological and physiological mechanisms (Cooney et al., 2013); and advice could also reduce depressive symptoms via reassurance and the correction of unhelpful beliefs regarding low back pain. The aim of the study was to estimate the extent to which depressive symptoms mediate the effect of physiotherapy treatment (i.e. exercise and advice) on pain and disability in a population with subacute low back pain. This involves estimating the effect of the intervention on depressive symptoms, and the effect of depressive symptoms on pain and disability.

\section{Methods}

This study is a secondary analysis of a factorial randomized controlled trial. The methods of the trial are described elsewhere (Pengel et al., 2007). The original study protocol was approved by the Institutional Review Board of the University of Sydney and relevant area health services, and was registered in the Australian Clinical Trials Registry (number 12605000039684). We registered and locked a prespecified analysis protocol for the current study on the "Open Science Framework" prior to data analysis (Baadjou, 2017). Our a priori protocol specified disability as the primary outcome that we later changed to pain as primary outcome and disability as secondary outcome to bring this analysis in line with the original trial.

\subsection{Participants}

Participants were recruited via advertisements in newspapers, invitations to hospital waiting lists for physiotherapy treatment of low back pain, or by direct referral by a healthcare professional. Persons between 18 and 80 years of age with nonspecific low back pain lasting for at least six weeks, but no longer than twelve weeks were included. Sixteen physiotherapists from seven clinics in Australia and New Zealand provided the intervention and control sessions.

\subsection{Intervention}

After providing informed consent, participants were allocated to one of four groups: exercise and advice; exercise and sham advice; sham exercise and advice; or sham exercise and sham advice. Participants received twelve sessions over six weeks. During three of the twelve sessions, participants received advice or sham advice. The exercise intervention consisted of an individualized program including supervised physical therapy incorporating principles of cognitive behavioral therapy as well as home exercises, tailored to the specific functional problems of each patient. Sham exercise involved deactivated pulsed ultrasonography and deactivated short-wave diathermy. Advice sessions aimed to encourage a graded return to normal activities in which therapists explained the benign nature of low back pain, addressed unhelpful beliefs, and emphasized the importance of staying active. In the sham advice session, the physiotherapist listened empathically to the participant, but did not give advice for their back pain (Pengel et al., 2007).

\subsection{Measures}

Baseline assessment captured demographic, social, and pain characteristics of the sample, as well as baseline values of the outcome measures, mediator and confounders. Assessment of the mediator and outcomes was repeated at six weeks and three months.

Mediator: Depressive symptoms were measured with the depression subscale of the Depression, Anxiety, Stress Scale-21 (DASS-21) (Lovibond and Lovibond, 1995). The DASS-21 measures the negative emotional states of depression, anxiety, and stress. The depression subscale includes 7 questions about dysphoria, hopelessness, devaluation of life, self-deprecation, lack of interest/involvement, anhedonia, and inertia. Subjects report the extent to which they have experienced these states in the past week on a 4-point scale (0-3). Score is multiplied by 2 , so that total score range is $0-42$. We used the baseline and six weeks score in the analysis. The scale is stable over time (Brown et al., 1997) and responsive to treatments directed at mood problems ( $\mathrm{Ng}$ et al., 2007).

Outcome measures: Outcomes were pain and disability. Average pain over the past week was measured on a numerical rating scale from 0 (no pain), to 10 (worst pain possible). Disability was measured using the Roland-Morris Disability Questionnaire (RMDQ) (Roland and Morris, 1983). The RMDQ consists of 24 items describing difficulties people encounter when experiencing back pain. Subjects indicated which of these difficulties they currently encountered (scale range 0-24). We used the baseline and three month scores in the analysis.

Potential confounders: We used a structural approach to identify potential confounders for the mediation-outcome effect (Shrier and Platt, 2008). The confounders were selected based on theoretical and empirical evidence including the fear-avoidance model, which specifies that catastrophizing thoughts, fear-avoidance beliefs, and depression play a role in the development of its associated disability and persistence of chronic pain (Vlaeyen and Crombez, 1999; Vlaeyen and Linton, 2012). Selected confounders were: age, gender, and baseline assessments of kinesiophobia, pain self-efficacy, and pain catastrophizing. Baseline assessments of the mediator and outcomes (depression, pain and disability) were also included in the models. Kinesiophobia was measured using the Tampa Scale of Kinesiophobia (TSK) (Miller et al., 1991). Scores range from 17 (low fear of movement) to 68 (high fear of movement). Pain self-efficacy was measured with the Pain Self-Efficacy Questionnaire (PSEQ) (Nicholas, 2007). Scores range 0 (low self-efficacy) to 60 (high self-efficacy). Pain catastrophizing was measured with the Pain-Related Self-Statements Scale, catastrophizing subscale (Flor et al., 1993). Scores range 0 (low) to 45 (high). Psychometric properties of these measures are within acceptable standards (Weermeijer and Meulders, 2018; Asghari and Nicholas, 2009; Flor et al., 1993).

\subsection{Statistical analysis}

\subsubsection{Descriptive statistics}

We present descriptive statistics for subjects who completed the baseline and one or both of the follow-up questionnaires. Baseline characteristics and outcome values with a normal distribution were presented as mean with their standard deviation (SD), non-normally distributed data were presented as medians with 25th-75th percentiles 


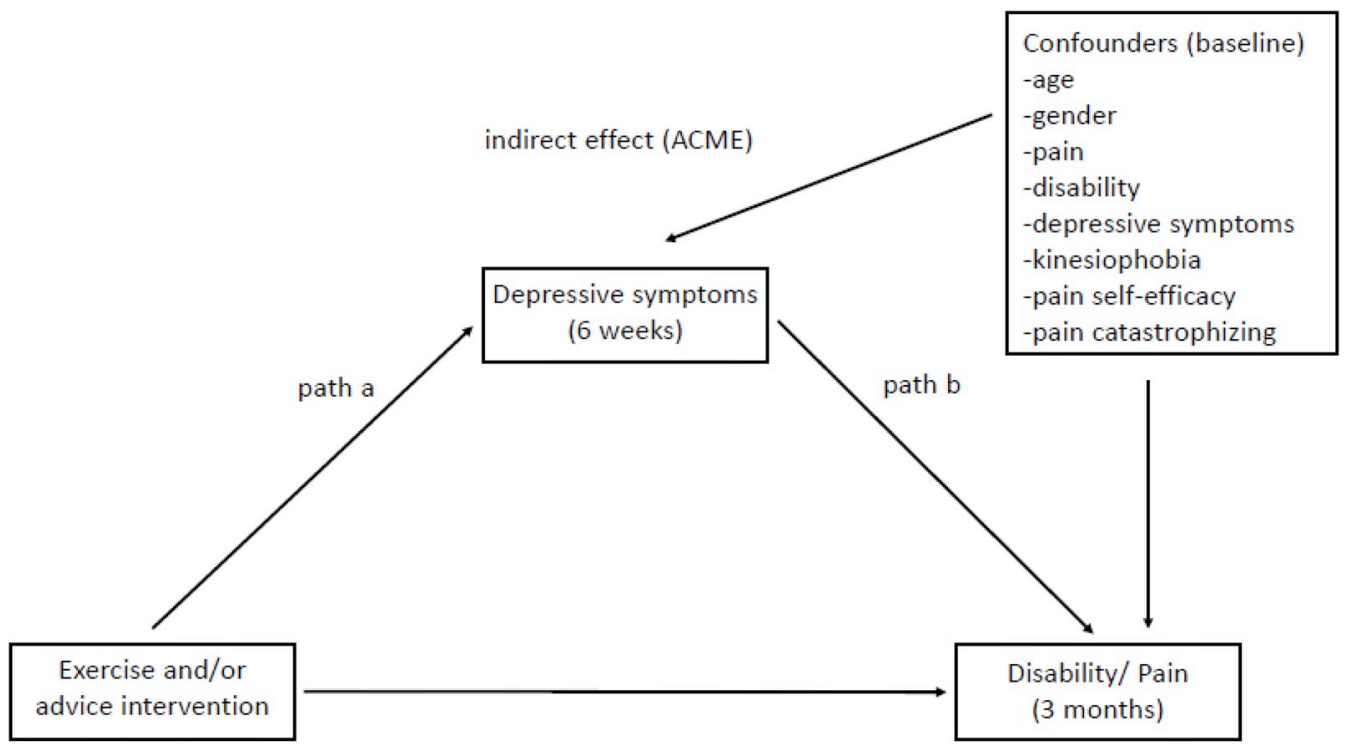

Fig. 1. Mediator model. Hypothesized causal mechanisms with outcome pain and disability. The indirect effect, or ACME, is the effect of the exposure (group allocation) on pain or disability, mediated by depressive symptoms. The direct effect, or ADE, is the remaining effect of the exposure on pain or disability that is not mediated through depressive symptoms. Path a is the effect of the exposure on depressive symptoms. Path b is the effect of depressive symptoms on pain or disability.

direct effect (ADE)

(interquartile range). We excluded subjects who were lost to follow-up at both six weeks and three months.

\subsubsection{Causal mediation analysis}

Mediation analyses were performed for complete cases. We conducted a causal mediation analysis under the counterfactual framework (Imai et al., 2010). We estimated the average causal mediation effect (ACME), average direct effect (ADE), and the total effect. The ACME is the effect of the exposure (group allocation) on the outcome (pain or disability) that is mediated by the hypothesized mediator (depressive symptoms). The effect of the exposure on the outcome that is not mediated through the selected mediator (depression) is represented by the ADE. Thus, the sum of the ACME and ADE equals the total effect. The proportion of the total effect that is channeled through the mediator (ACME) is expressed as the proportion mediated (Imai et al., 2010). We estimated unstandardized point estimates of the ACME, ADE and total effect and their 95\% confidence intervals using 1000 bootstrapped stimulations.

We constructed six single mediator models to quantify the ACME, ADE and total effect for each model. These models are outlined in Appendix 1. For each outcome (pain and disability), we specified three models with the exposure defined as: 1 : exercise and advice versus sham; 2: exercise versus sham; 3 : advice versus sham. If the confidence intervals surrounding the point estimate for ACME included 0, we aimed to identify where the causal path broke down. We did this to understand why the intervention did not work through depressive symptoms. To do so, we fit two linear regression models: the mediator model (path a) and the outcome model (path b). We constructed the mediator model with exposure as the independent variable and the mediator as the dependent variable. The outcome model was specified with the exposure, mediator, exposure-mediator interaction term, and selected confounders as independent variables, and the outcome as the dependent variable (VanderWeele, 2015). Fig. 1 provides an overview of all causal models.

\subsubsection{Sensitivity analyses for sequential ignorability}

Because the exposure was randomly allocated, one can assume that the exposure-mediator and exposure-outcome effects are unconfounded. However, it is possible that the mediator-outcome effect could be confounded by unknown/unmeasured confounders (Imai et al., 2010). Therefore, we conducted sensitivity analyses to assess the robustness of the ACME to the effects of unknown/unmeasured confounders. The level of confounding due to unknown/unmeasured confounders is represented by the correlation between the residuals from the mediator and outcome regression models (rho). We explored how varying levels of rho between -1 and 1 influenced the ACME by plotting the results. Analyses were performed using the "mediation" package in $\mathrm{R}$ (The $\mathrm{R}$ Foundation for Statistical Computing) (Tingley et al., 2014).

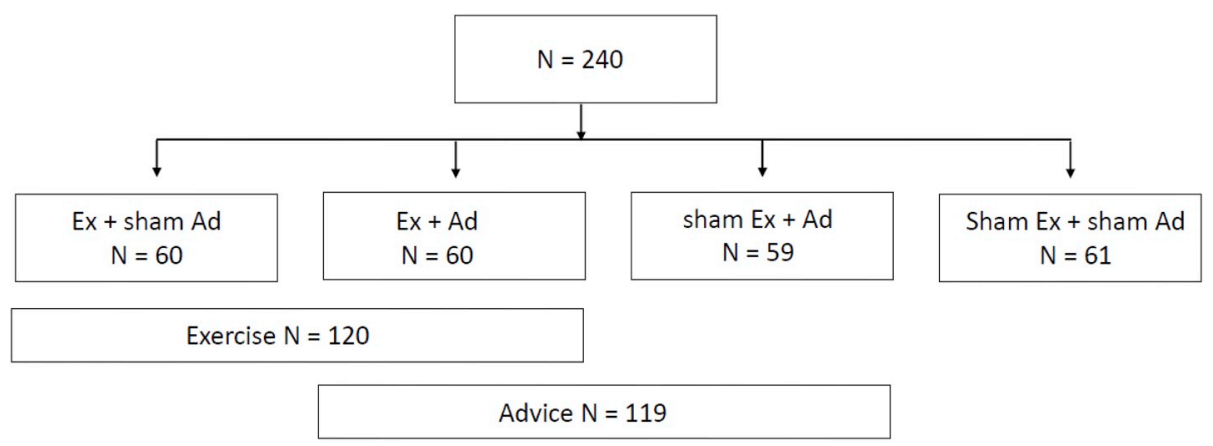

Fig. 2. Participant flow chart. Ex: exercise, Ad: advice. 


\section{Results}

\subsection{Participant characteristics}

After excluding cases lost to-follow-up at both six weeks and three months, 240 participants remained from 259 participants in the original trial. In this sample, 60 received exercise and advice, 60 received exercise and sham advice, 59 received sham exercise and advice, and 61 received sham exercise and sham advice. In total, 120 received exercise, and 119 received advice (Fig. 2). Average age was 50.5 (SD 15.6) years, and $52 \%$ were male. Co-occurrence of leg pain was reported by $31.7 \%$. Previous episode of back pain was experienced by $66.1 \%$. Current regular exercise was practiced by $54.4 \%$. Mean pain score at baseline was 5.4 (SD 2.0). Mean disability score at baseline was 8.4 (SD 4.9). Median depression score at baseline was 4 (IQR 2-12) (Table 1).

\subsection{Mediation analyses}

\subsubsection{Pain outcome (models 1,2 \& 3)}

From a sample of 225 complete cases for the pain outcome, we found that depressive symptoms did not mediate the effect of exercise plus advice on pain (ACME -0.05 [95\%CI -0.24 to 0.15$]$ ). Most of the total effect $(-1.23$ [-1.94 to -0.49$])$ was mediated through unknown mechanisms (ADE -1.19 [-1.85 to - 0.48]). For exercise alone and advice alone, there was also no significant mediating effect of depressive symptoms: exercise (ACME -0.09 [-0.29 to 0.05]), advice (ACME 0.005 [-0.17 to 0.19]). For exercise alone, the $\operatorname{ADE}(-0.50$ [-1.09 to 0.12]) and total effect $(-0.60$ [-1.21 to 0.06$])$ were not significant. For advice alone, the ADE ( $-0.82[-1.39$ to -0.21$])$ and total effect $(-0.81[-1.42$ to -0.20$]$ ) were not significant. See Fig. 3 .

None of the exposures (combined exercise and advice, exercise

Table 1

Baseline characteristics.

\begin{tabular}{|c|c|c|c|c|}
\hline & Exercise only & Advice only & Exercise + Advice & Sham exercise + Sham advice \\
\hline No. of participants & 120 & 119 & 60 & 61 \\
\hline Age (years) & 49.7 (SD 15.9) & 51.1 (SD 15.5) & 50.5 (SD 15.7) & $51.1(\mathrm{SD} 15.4)$ \\
\hline Gender, male & $63(52.5 \%)$ & $65(54.6 \%)$ & $32(53.3 \%)$ & $28(45.9 \%)$ \\
\hline Working before low back pain (yes) & $70(58.3 \%)$ & $69(58 \%)$ & $37(61.7 \%)$ & $30(49.2 \%)$ \\
\hline Currently working & $62(51.7 \%)$ & $62(52.1 \%)$ & $33(55 \%)$ & $26(42.6 \%)$ \\
\hline Currently smoking & $18(15 \%)$ & $18(15.1 \%)$ & $11(18.3 \%)$ & $14(23 \%)$ \\
\hline Currently performs regular exercise & $67(55.8 \%)$ & $66(56.4 \%)$ & $32(53.3 \%)$ & $28(46.7 \%)$ \\
\hline Previous episodes of low back pain & $78(65 \%)$ & $83(70.3 \%)$ & $42(70 \%)$ & $39(63.9 \%)$ \\
\hline Pain referred to the leg & $35(29.2 \%)$ & $40(33.6 \%)$ & $17(28.3 \%)$ & $18(29.5 \%)$ \\
\hline Pain in other areas (neck, shoulder) & $27(22.5 \%)$ & $25(21 \%)$ & $11(18.3 \%)$ & $8(13.1 \%)$ \\
\hline Low back pain treatment ( $<6 \mathrm{wks})$ & $65(54.2 \%)$ & $63(52.9 \%)$ & $35(58.3 \%)$ & $29(47.5 \%)$ \\
\hline Taking pain medication ( $<6 \mathrm{wks}$ ) & $65(54.2 \%)$ & $70(59.8 \%)$ & $33(56.9 \%)$ & $39(63 \%)$ \\
\hline Pain severity last week & $5.3(\mathrm{SD} 2.1)$ & $5.4(\mathrm{SD} 2.1)$ & $5.4(\mathrm{SD} 2.2)$ & 5.4 (SD 1.8) \\
\hline RMDQ score & $8.6(\mathrm{SD} 4.9)$ & $8.6(\mathrm{SD} 4.6)$ & $8.9(\mathrm{SD} 4.8)$ & $8.2($ SD 5.5) \\
\hline DASS-Depression & 4 (IQR 0-10) & 4 (IQR 0-10) & 4 (IQR 0-8) & 4 (IQR 2-14) \\
\hline DASS-Anxiety & 2 (IQR 0-8) & 2 (IQR 0-8) & 2 (IQR 0-6) & 2 (IQR 0-8) \\
\hline DASS-Stress & 10 (IQR 4-18) & 10 (IQR 4-16) & 8 (IQR 4-12) & 10 (IQR 2-18) \\
\hline TSK score & 39.1 (SD 8.4) & $39.1($ SD 7.8$)$ & $38.9(\mathrm{SD} 8.0)$ & 38.5 (SD 8.2) \\
\hline PSE score & 44.5 (SD 11.9) & 45.3 (SD 11.7) & 44.7 (SD 12.4) & 43.3(SD 13.7) \\
\hline PRSS catastrophizing & $17.5(\mathrm{SD} 8.8)$ & $17.6(\mathrm{SD} 9.8)$ & $17.2(\mathrm{SD} 9.2)$ & $18.5($ SD 7.7) \\
\hline
\end{tabular}

Variables are presented as n (\%), mean(standard deviation or SD), or median with interquartile range, IQR). RMDQ: Roland Morris Disability Questionnaire; DASS: Depression, Anxiety, Stress Scales-21; TSK: Tampa Scale for Kinesiophobia (TSK); PSE: Pain Self-Efficacy questionnaire; PRSS: Pain-Related Self-Statements Scale.

According to the DASS cut-off scores by Lovibond and Lovibond (1995), 69.6\% scored no depressive symptoms (score $<10$ ), 9.6\% had mild (score 10-13), $12.5 \%$ had moderate (14-20), and $8.3 \%$ had severe or extremely severe $(21+)$ depressive symptoms. At 6 weeks, median depression score was 0 (0-6); 83.6 had no depressive symptoms, 4.7\% had mild, $6.5 \%$ had moderate, and $5.2 \%$ had severe or extremely severe depressive symptoms (Table 2).

Table 2

Depressive symptoms score (DASS).

\begin{tabular}{lll}
\hline Depressive symptoms & baseline & 6 weeks \\
\hline None & $69.6 \%$ & $83.6 \%$ \\
Mild & $9.6 \%$ & $4.7 \%$ \\
Moderate & $12.5 \%$ & $6.5 \%$ \\
Severe/extremely & $8.3 \%$ & $5.2 \%$ \\
\hline
\end{tabular}

alone, or advice alone) compared to placebo, had an effect on depressive symptoms (path a). Whereas the association between change in depressive symptoms and pain (path b) was significant for exercise combined with advice (regression coefficient $=0.06$ [SE 0.03]) and advice alone (regression coefficient $=0.07$ [SE 0.04]). For exercise alone, the association was of similar magnitude but not significant (regression coefficient $=0.06$ [SE 0.04]).

\subsubsection{Disability outcome (models 4,5 \& 6)}

From a sample of 225 cases for the disability outcome, we found that depressive symptoms did not mediate the effect of exercise and advice on disability (ACME -0.10 [95\%CI -0.59 to 0.38$]$ ). The ADE $(-1.70[-2.89$ to -0.57$])$ and the total effect $(-1.80$ [-3.09 to -0.47$]$ were significant. For exercise alone and advice alone, there was also no significant mediating effect of depressive symptoms: exercise (ACME -0.23 [-0.61 to 0.11]), advice (ACME 0.005 [-0.39 to 0.36]). For exercise alone, there was no significant ADE or total effects (ADE -0.46 
[-1.41 to 0.52$]$, total effect -0.69 [-1.70 to 0.39$])$. For advice alone, there were significant $\operatorname{ADE}(-1.30[-2.28$ to -0.28$])$ and total effects $(-1.30[-2.31$ to -0.28$]$ ). See Fig. 4 . None of the exposures (combined exercise and advice, exercise alone, or advice alone) had an effect on depressive symptoms (path a). Whereas the association between change in depressive symptoms and disability (path b) was significant for all three exposures: exercise and advice (regression coefficient $=0.17$ [SE $0.05]$ ), exercise (regression coefficient $=0.16$ [SE 0.05]), advice (regression coefficient $=0.16$ [SE 0.06]) $($ Table 3 ).
Exercise and advice VS No exercise or advice

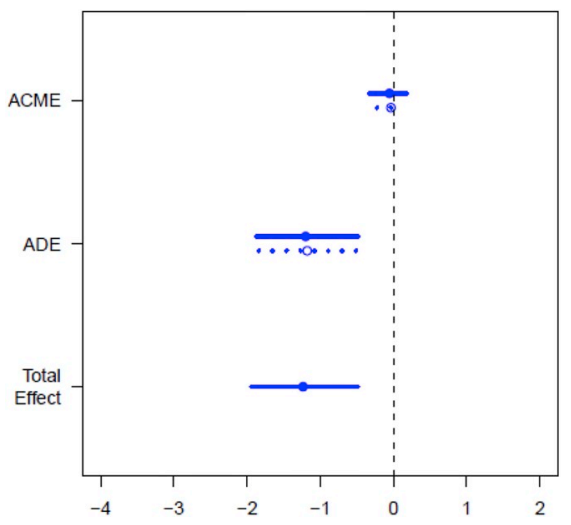

Exercise VS No exercise

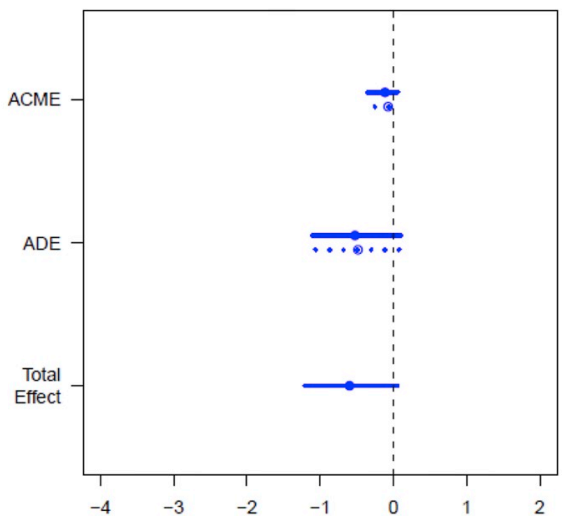

Advice VS No advice

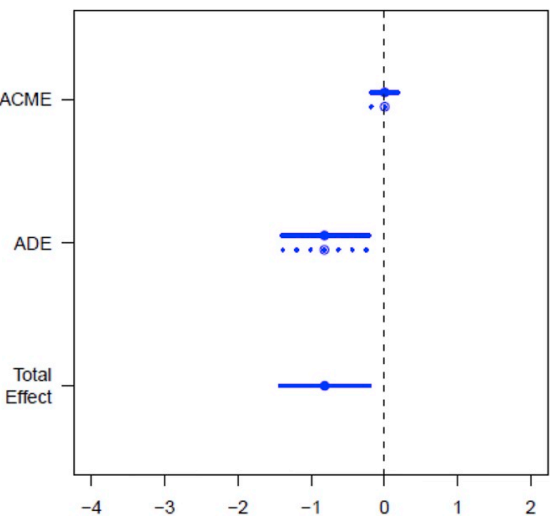

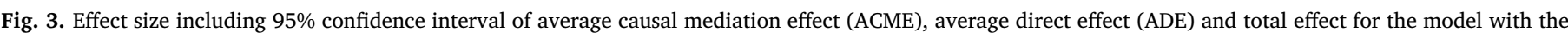

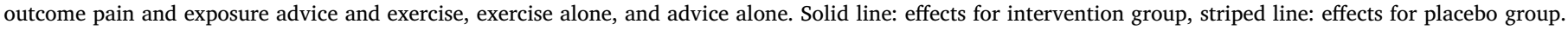
Significant effects are visualized by a $95 \%$ confidence interval not including 0 .

Exercise and advice VS No exercise or advice

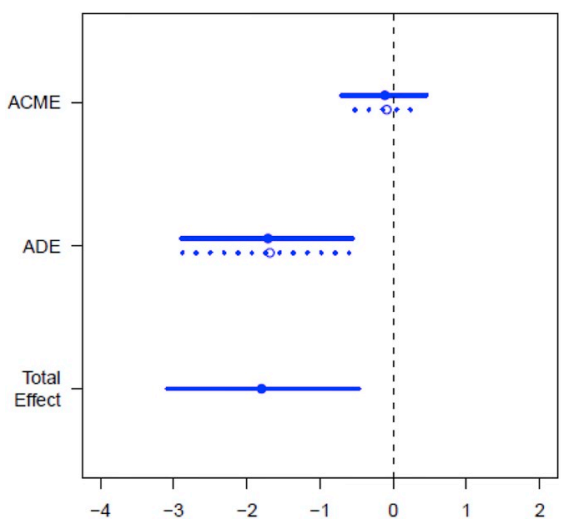

Exercise VS No exercise

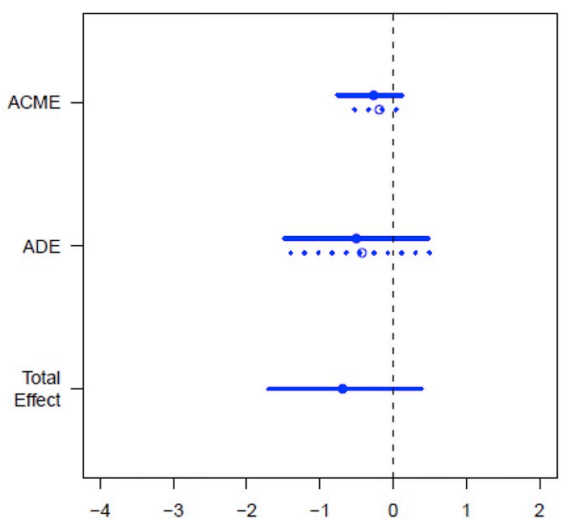

Advice VS No advice

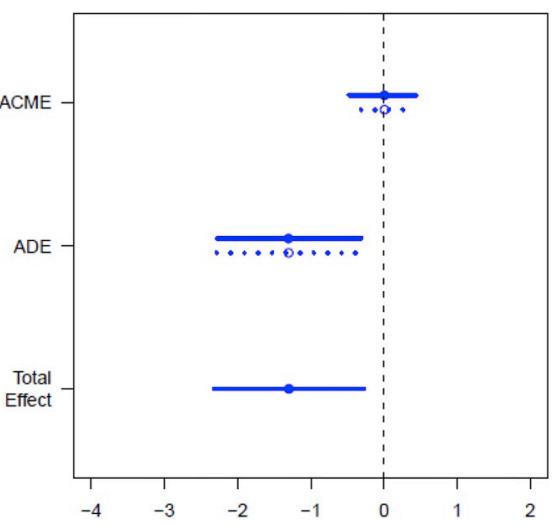

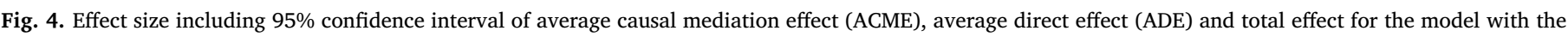

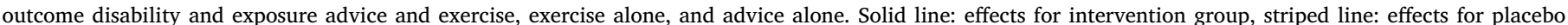
group. Significant effects are visualized by a $95 \%$ confidence interval not including 0 . 
Table 3

Mediation effects.

\begin{tabular}{|c|c|c|c|c|c|}
\hline & Total effect & $\mathrm{ADE}$ & ACME & Path a & Path b \\
\hline \multicolumn{6}{|l|}{ Model 1 (pain) } \\
\hline $\begin{array}{l}\text { Average effect } \\
\text { Adex vs. no adex }\end{array}$ & $\begin{array}{l}-1.23 \\
(-1.94 \text { to } 0.49)^{*}\end{array}$ & $\begin{array}{l}-1.19 \\
(-1.85 \text { to } 0.48)^{*}\end{array}$ & $\begin{array}{l}-0.05 \\
(-0.24 \text { to } 0.15)\end{array}$ & -0.17 SE 1.16 & 0.06 SE $0.03^{*}$ \\
\hline \multicolumn{6}{|l|}{ Model 2 (pain) } \\
\hline $\begin{array}{l}\text { Average effect } \\
\text { Ex vs. no ex }\end{array}$ & $\begin{array}{l}-0.60 \\
(-1.21 \text { to } 0.06)\end{array}$ & $\begin{array}{l}-0.50 \\
(-1.09 \text { to } 0.12)\end{array}$ & $\begin{array}{l}-0.09 \\
(-0.29 \text { to } 0.05)\end{array}$ & -1.12 SE 1.01 & 0.06 SE 0.04 \\
\hline \multicolumn{6}{|l|}{ Model 3 (pain) } \\
\hline $\begin{array}{l}\text { Average effect } \\
\text { Ad vs. no ad } \\
\text { Model } 4 \text { (disability) }\end{array}$ & $\begin{array}{l}-0.81 \\
(-1.42 \text { to } 0.20)^{*}\end{array}$ & $\begin{array}{l}-0.82 \\
(-1.39 \text { to } 0.21)^{*}\end{array}$ & $\begin{array}{l}0.005 \\
(-0.17 \text { to } 0.19)\end{array}$ & 0.60 SE 1.01 & 0.07 SE $0.04^{*}$ \\
\hline $\begin{array}{l}\text { Average effect } \\
\text { Adex vs. no adex }\end{array}$ & $\begin{array}{l}-1.80 \\
(-3.09 \text { to } 0.47)^{*}\end{array}$ & $\begin{array}{l}-1.70 \\
(-2.89 \text { to } 0.57)^{*}\end{array}$ & $\begin{array}{l}-0.10 \\
(-0.59 \text { to } 0.38)\end{array}$ & -0.17 SE 1.16 & 0.17 SE $0.05^{*}$ \\
\hline \multicolumn{6}{|l|}{ Model 5 (disability) } \\
\hline $\begin{array}{l}\text { Average effect } \\
\text { Ex vs. no ex }\end{array}$ & $\begin{array}{l}-0.69 \\
(-1.70 \text { to } 0.39)\end{array}$ & $\begin{array}{l}-0.46 \\
(-1.41 \text { to } 0.52)\end{array}$ & $\begin{array}{l}-0.23 \\
(-0.61 \text { to } 0.11)\end{array}$ & -1.12 SE 1.01 & 0.16 SE $0.05^{*}$ \\
\hline \multicolumn{6}{|l|}{ Model 6 (disability) } \\
\hline $\begin{array}{l}\text { Average effect } \\
\text { Ad vs. no ad }\end{array}$ & $\begin{array}{l}-1.30 \\
(-2.31 \text { to } 0.28)^{*}\end{array}$ & $\begin{array}{l}-1.30 \\
(-2.28 \text { to } 0.28)^{*}\end{array}$ & $\begin{array}{l}0.005 \\
(-0.39 \text { to } 0.36)\end{array}$ & 0.60 SE 1.01 & 0.16 SE 0.06 \\
\hline
\end{tabular}

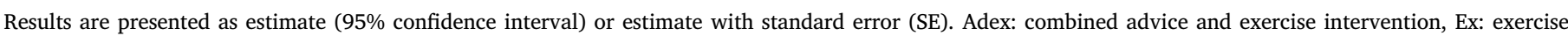

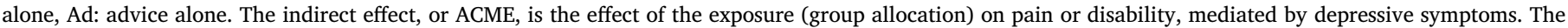

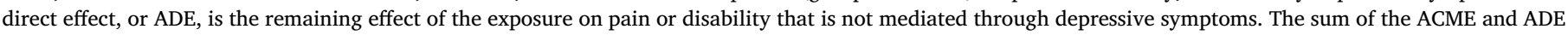

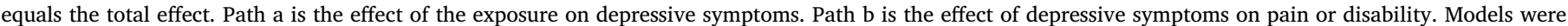

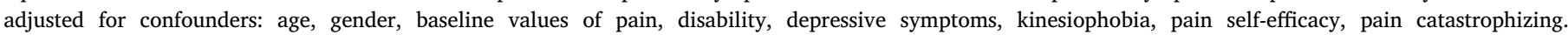
$*=\mathrm{p}<0.05$.

\subsubsection{Sensitivity analysis for sequential ignorability}

All six sensitivity analyses indicated that our estimates of the ACME were robust to the influence of potential unknown/unmeasured confounders. Even when we assume a large magnitude of unknown confounding effects (rho at the extremes of -1 and 1), the ACME only varied by a small magnitude (Appendi $\times 2$ and 3 ).

\subsubsection{Post-hoc sensitivity analysis}

A visual inspection of the distribution of depression scores showed a large peak at 0 (zero-inflated). We conducted a post-hoc sensitivity analysis to check whether modelling the mediator using a negative binominal regression model would change the results of the effect of the exposure on the mediator (path a). The negative binominal model produced a regression coefficient of -0.04 (SE 0.31) for the exercise and advice intervention, -0.26 (SE 0.27 ) for the exercise alone intervention, and 0.14 (SE 0.27) for the advice alone intervention. These effect sizes approximated the coefficients of the linear regression models in the original analysis.

\section{Discussion}

Depressive symptoms did not mediate the effect of exercise and/or advice on pain and disability in patients with subacute low back pain. A likely explanation for this is due to the lack of effect of exercise and advice on depressive symptoms. Second, we found a positive relationship between depressive symptoms at week six, and pain and disability at three months. This suggests that people with subacute low back pain and depressive symptoms could benefit from a targeted approach that specifically addresses depressive symptoms.

An interesting finding is that level of depressive symptoms in our sample were comparable to normative data for the Australian population (Lovibond and Lovibond, 1995). About seventy percent in our sample did not experience depressive symptoms, ten percent reported mild levels, and twenty percent reported moderate to severe levels of depressive symptoms. This is in contrast to the strong evidence that exists that depressive symptoms are elevated in acute low back pain (Shaw et al., 2016). The limited representation of people with moderate to severe levels of depression may explain the absence of a mediating effect through depression. Mansell et al. (2016) evaluated the working mechanisms of a psychologically informed physiotherapy treatment for a subgroup of low back pain patients with high risk of poor outcome. Mansell et al. combined catastrophizing, fear-avoidance, anxiety and depression into a single mediator, labelled, pain-related distress. In this high risk group, the authors found that pain-related distress mediated the effect of the treatment (Mansell et al., 2016). The discrepancy between the findings of Mansell et al. (2016) and our current study might be an indication of the importance of stratified primary care based on the patient's risk of persistent disabling pain as levels of depressive symptoms are a factor in currently widely used screening tools, such as the STarT Back (Hill et al., 2008).

The association between depressive symptoms at week 6 and pain and disability scores at three months suggests that people with subacute low back pain could benefit from a targeted approach that specifically addresses depressive symptoms. Insights into the treatment of subacute low back pain have emerged over recent years since publication of the original trial some 10 years ago. For example, a systematic review provided strong evidence that patient education reduced psychological distress and use of health care related to acute low back pain (Traeger et al., 2015). Also, the effects of other interventions ranging from education and advice, brief interventions with light mobilization, diverse exercise programs, graded activity, psychological counselling and mulitidisciplinary biopsychosocial rehabilitation for subacte low back pain are still debated (Marin et al., 2017). Although guidelines recommend that low back pain should be managed in primary care, 
providing education and advice to stay active and at work, using a biopsychosocial framework, this is often not the reality in clinical practice (Foster et al., 2018). Improved and better integrated education of health-care professionals could support implementation of practice guidelines for low back pain (Foster et al., 2018). Results from this study provide more insight in working mechanisms of exercise and advice in the treatment of subacute low back pain in primary care, therewith providing researchers with new hypothesis for further research to improve treatment and providing clinicians with more understanding of working mechanisms of treatment in clinical practice.

\subsection{Strength and weaknesses}

The strength of this study is the application of causal mediation analysis to a well-conducted large randomized, placebo-controlled, clinical trial. This design allows for a rigorous evaluation of working mechanisms of an intervention. By using causal mediation analysis, we have provided estimates that are based on causal definitions while explicitly outlining the assumptions that are required for causal interpretation. A limitation is that our sample consisted of a small percentage of patients with moderate or severe depressive symptoms. This may explain the lack of mediating effect through depressive symptoms. Second, the original study wasn't designed for mediation analysis and the design was posthoc. Further, we deviated from our a priori protocol by conducting additional analyses with pain intensity as the outcome. Finally, we were unable to account for the zero-inflated distribution of the mediator in our causal mediation analysis due to software limitations. However, our sensitivity analysis of the exposure-mediator effect to account for the zero-inflated distribution approximated the results from the original analysis.

Appendix 1. Summary of mediator models

\subsection{Directions for future research}

The significant direct effect indicates that there are other mediators responsible for the effect of exercise and/or advice on pain and disability in subacute low back pain. There are other theories that could be tested, for example the mediating role of pain catastrophizing and selfefficacy. Further, sampling a wider distribution of patients with high and low levels of depressive symptoms might provide better insight into the mediating role of depressive symptoms. Future trials testing the efficacy of exercise and advice should plan and design a priori mediation analyses to identify mediators.

In conclusion, depressive symptoms did not mediate the effect of an exercise and/or advice intervention on pain or disability in patients with subacute low back pain with relatively low levels of depressive symptoms. However depressive symptoms were associated with pain and disability after the adjustment for possible confounders.

\section{Author's contributions}

Conception and design: V. Baadjou, H. Lee, S. Kamper. Analysis of data: V. Baadjou, H. Lee. Interpretation of data: V. Baadjou, H. Lee, S. Kamper, R. Smeets. Drafting of the article, critical revision and final approval: V. Baadjou, H. Lee, S. Kamper, R. Smeets.

S. Kamper's and H. Lee's research is supported by the National Health and Medical Research Council of Australia. The authors have nothing to disclose.

\section{Acknowledgments}

The authors thank the original trial team (Liset Pengel, Kathryn Refshauge, Christopher Maher, Michael Nicholas, Robert Herbert, Peter McNair) for supplying data.

\begin{tabular}{|c|c|c|c|c|c|}
\hline $\begin{array}{l}\text { Model } \\
\text { no. }\end{array}$ & Exposure & Mediator & Outcome & Confounders of mediator-outcome path & Interaction term \\
\hline 1 & $E x+$ Ad vs. shamEx + shamAd & $\begin{array}{l}\text { Depressive } \\
\text { symptoms (6 } \\
\text { weeks) }\end{array}$ & $\begin{array}{l}\text { Pain ( } 3 \\
\text { months) }\end{array}$ & $\begin{array}{l}\text { Age, gender, and baseline values of pain, disability, depressive } \\
\text { symptoms, kinesiophobia, pain self-efficacy, pain catastro- } \\
\text { phizing }\end{array}$ & $\begin{array}{l}\text { Exercise and advice versus } \\
\text { sham } \mathrm{x} \text { depressive symp- } \\
\text { toms }\end{array}$ \\
\hline 2 & $\begin{array}{l}(E x+A d)+(E x+\text { shamAd }) \text { vs. } \\
(\text { shamEx }+ \text { Ad })+(\text { shamEx }+ \text { shamAd })\end{array}$ & $\begin{array}{l}\text { Depressive } \\
\text { symptoms (6 } \\
\text { weeks) }\end{array}$ & $\begin{array}{l}\text { Pain ( } 3 \\
\text { months) }\end{array}$ & $\begin{array}{l}\text { Age, gender, baseline values of pain, disability, depressive } \\
\text { symptoms, kinesiophobia, pain self-efficacy, pain catastro- } \\
\text { phizing }\end{array}$ & $\begin{array}{l}\text { Exercise versus sham } \mathrm{x} \text { de- } \\
\text { pressive symptoms }\end{array}$ \\
\hline 3 & $\begin{array}{l}(E x+A d)+(\text { shamEx }+ \text { Ad }) \text { vs. } \\
(E x+\text { shamAd })+(\text { shamEx }+ \text { shamAd })\end{array}$ & $\begin{array}{l}\text { Depressive } \\
\text { symptoms (6 } \\
\text { weeks) }\end{array}$ & $\begin{array}{l}\text { Pain (3 } \\
\text { months) }\end{array}$ & $\begin{array}{l}\text { Age, gender, and baseline values of pain, disability, depressive } \\
\text { symptoms, kinesiophobia, pain self-efficacy, pain catastro- } \\
\text { phizing }\end{array}$ & $\begin{array}{l}\text { Advice versus sham } \mathrm{x} \text { de- } \\
\text { pressive symptoms }\end{array}$ \\
\hline 4 & Ex + Ad vs. shamEx + shamAd & $\begin{array}{l}\text { Depressive } \\
\text { symptoms (6 } \\
\text { weeks) }\end{array}$ & $\begin{array}{l}\text { Disability } \\
\text { ( } 3 \text { months) }\end{array}$ & $\begin{array}{l}\text { Age, gender, and baseline values of pain, disability, depressive } \\
\text { symptoms, kinesiophobia, pain self-efficacy, pain catastro- } \\
\text { phizing }\end{array}$ & $\begin{array}{l}\text { Exercise and advice versus } \\
\text { sham } \mathrm{x} \text { depressive symp- } \\
\text { toms }\end{array}$ \\
\hline 5 & $\begin{array}{l}(E x+A d)+(E x+\text { shamAd }) \text { vs. } \\
(\text { shamEx }+ \text { Ad })+(\text { shamEx }+ \text { shamAd })\end{array}$ & $\begin{array}{l}\text { Depressive } \\
\text { symptoms (6 } \\
\text { weeks) }\end{array}$ & $\begin{array}{l}\text { Disability } \\
\text { ( } 3 \text { months) }\end{array}$ & $\begin{array}{l}\text { Age, gender, and baseline values of pain, disability, depressive } \\
\text { symptoms, kinesiophobia, pain self-efficacy, pain catastro- } \\
\text { phizing }\end{array}$ & $\begin{array}{l}\text { Exercise versus sham } \mathrm{x} \text { de- } \\
\text { pressive symptoms }\end{array}$ \\
\hline 6 & $\begin{array}{l}(E x+A d)+(\text { shamEx }+ \text { Ad }) \text { vs. } \\
(E x+\text { shamAd })+(\text { shamEx }+ \text { shamAd })\end{array}$ & $\begin{array}{l}\text { Depressive } \\
\text { symptoms (6 } \\
\text { weeks) }\end{array}$ & $\begin{array}{l}\text { Disability } \\
\text { ( } 3 \text { months) }\end{array}$ & $\begin{array}{l}\text { Age, gender, and baseline values of pain, disability, depressive } \\
\text { symptoms, kinesiophobia, pain self-efficacy, pain catastro- } \\
\text { phizing }\end{array}$ & $\begin{array}{l}\text { Advice versus sham } \mathrm{x} \text { de- } \\
\text { pressive symptoms }\end{array}$ \\
\hline
\end{tabular}

Ex: exercise, Ad: advice, shamEx: sham exercise, shamAd: sham advice. 
Appendix 2

\section{Exercise and advice VS No exercise or advice}

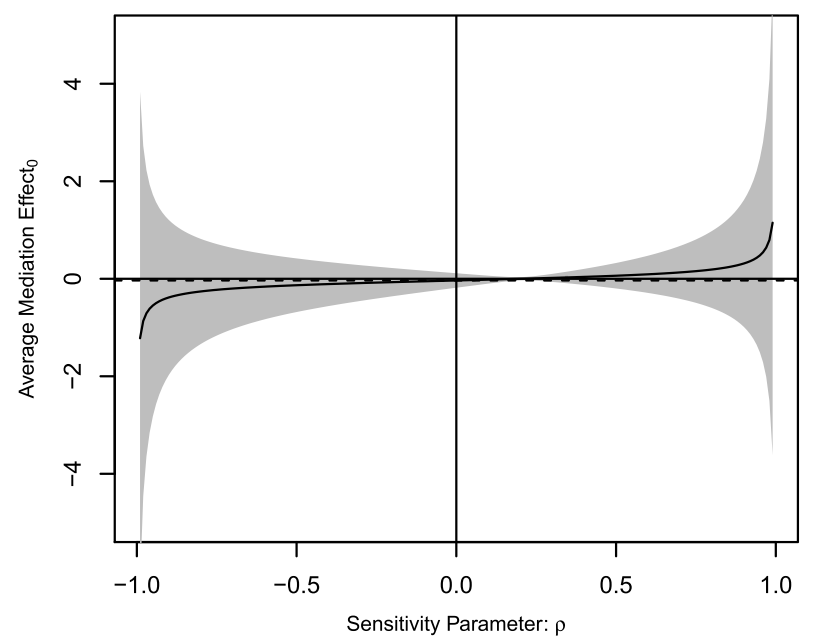

Exercise VS No exercise

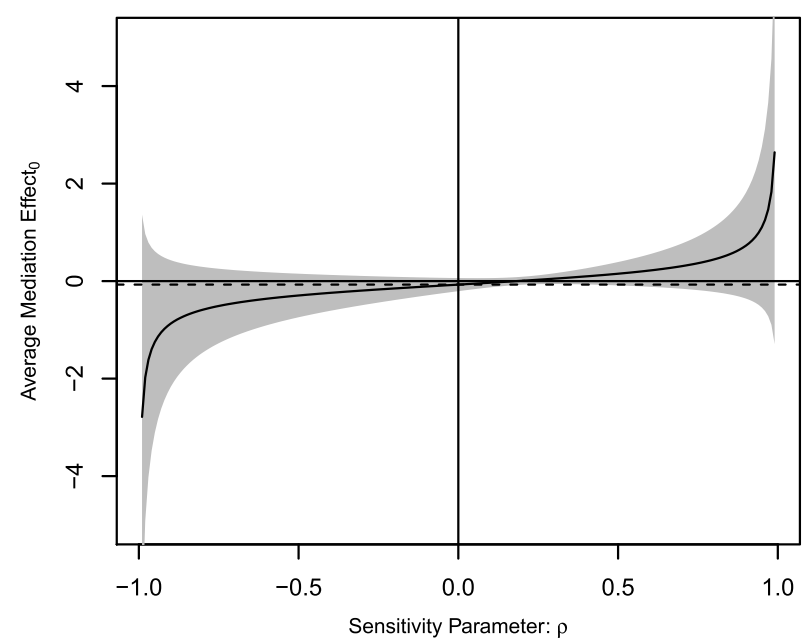

Advice VS No advice

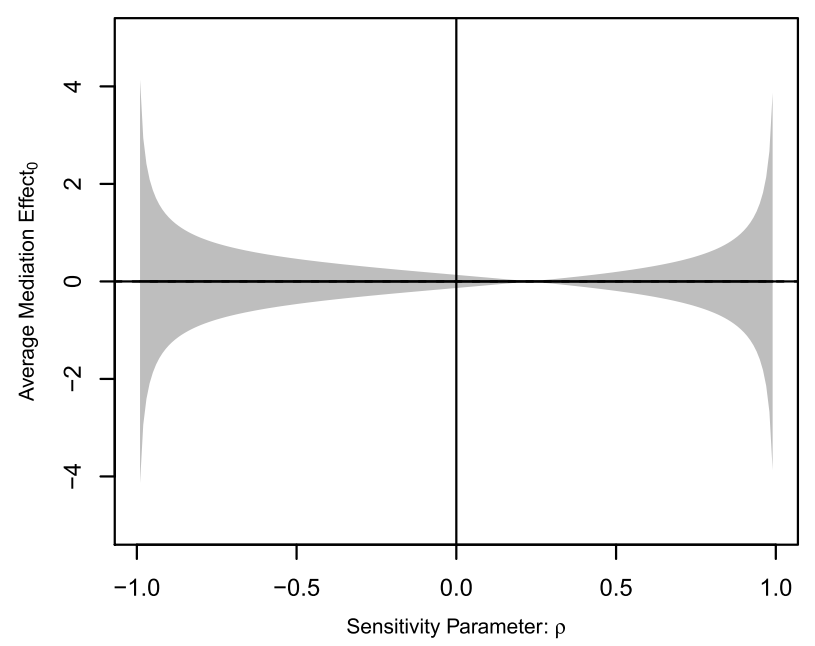

Exercise and advice VS No exercise or advice

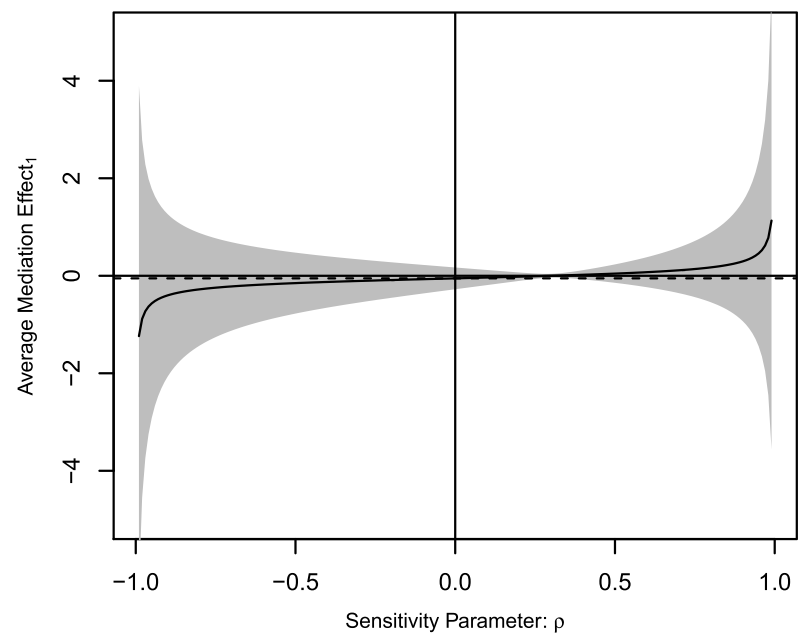

Exercise VS No exercise

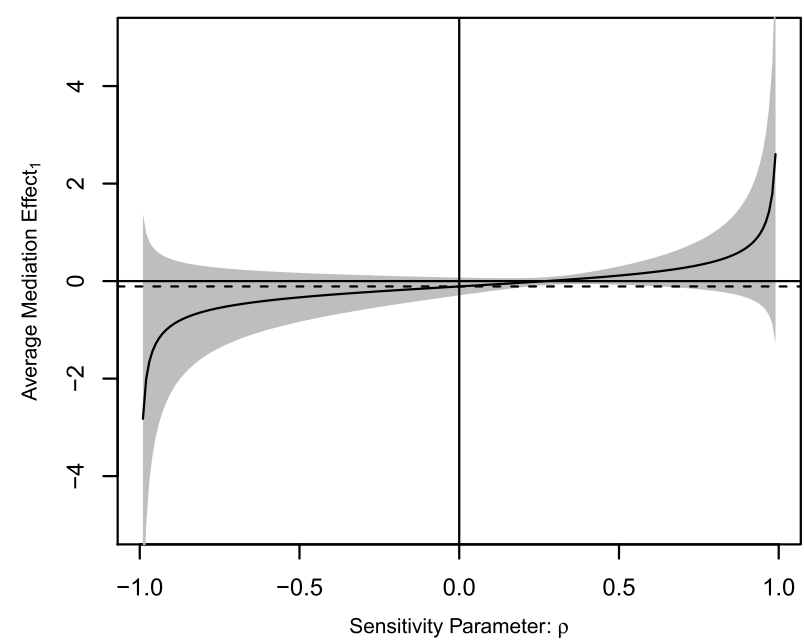

Advice VS No advice

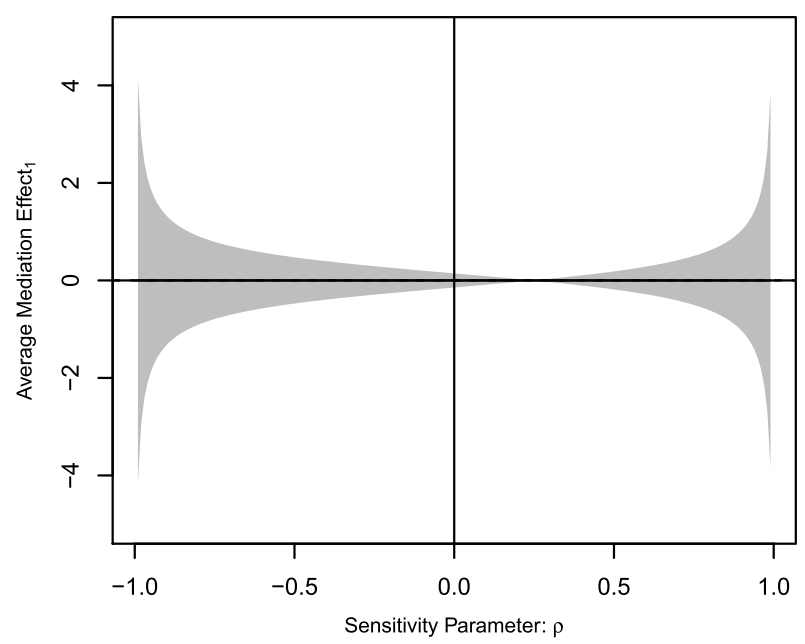


Appendix 3

Exercise and advice VS No exercise or advice

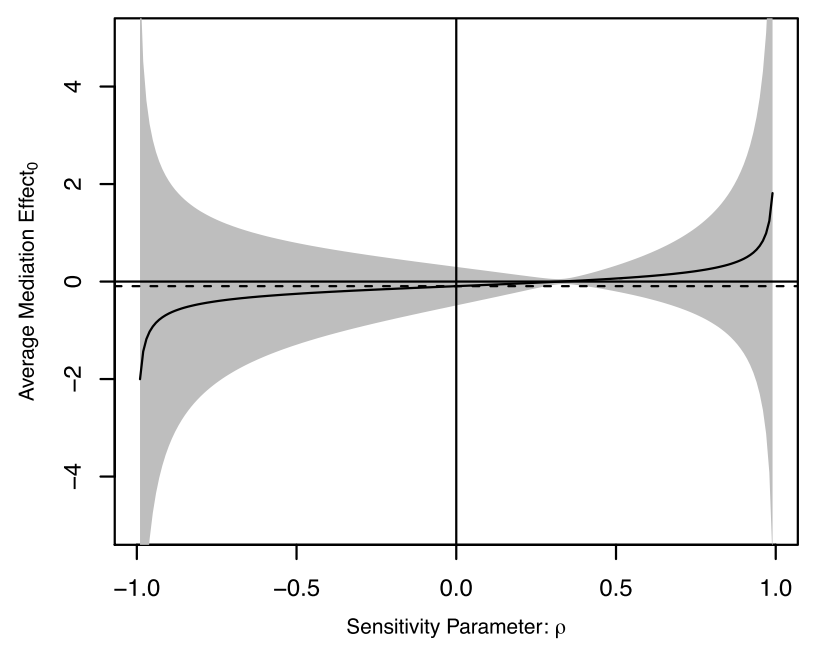

Exercise VS No exercise

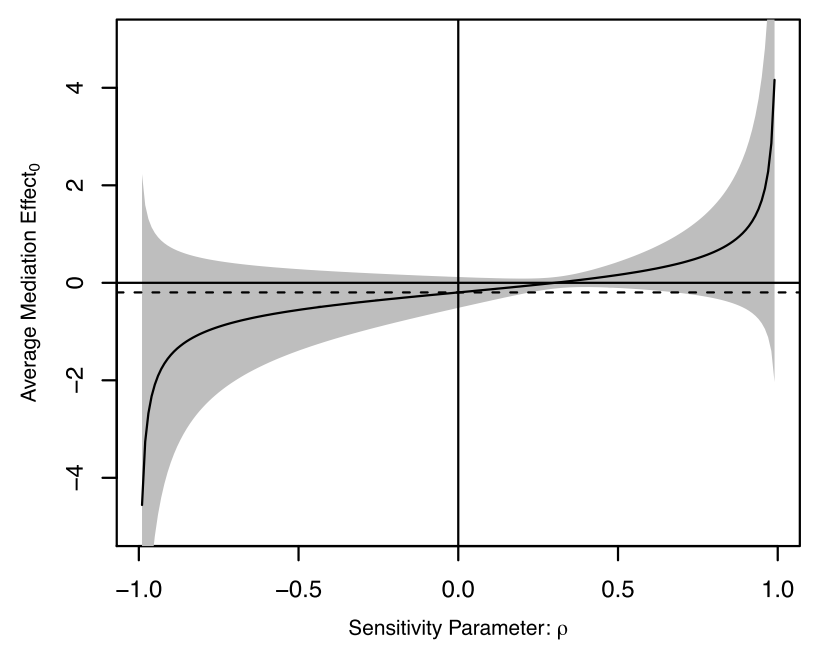

Advice VS No advice

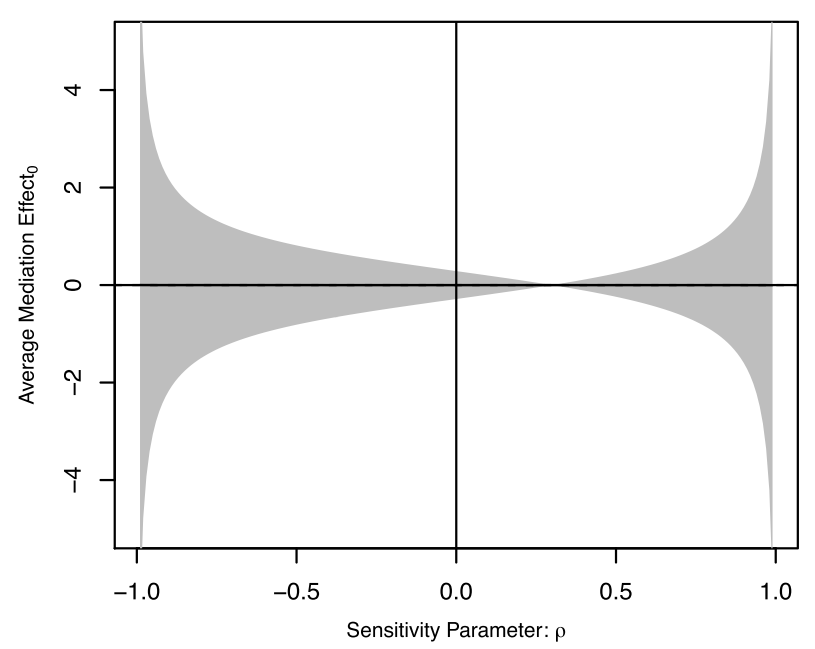

Exercise and advice VS No exercise or advice

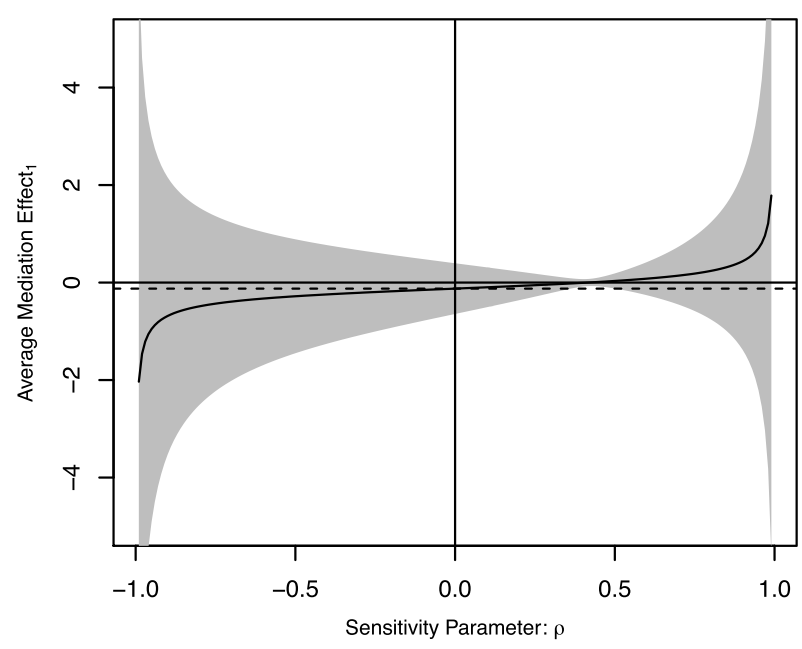

Exercise VS No exercise

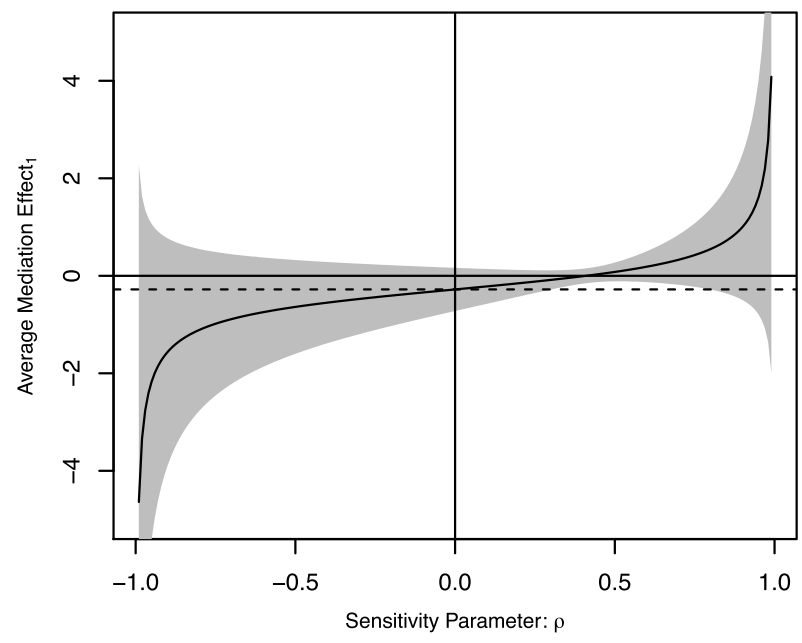

Advice VS No advice

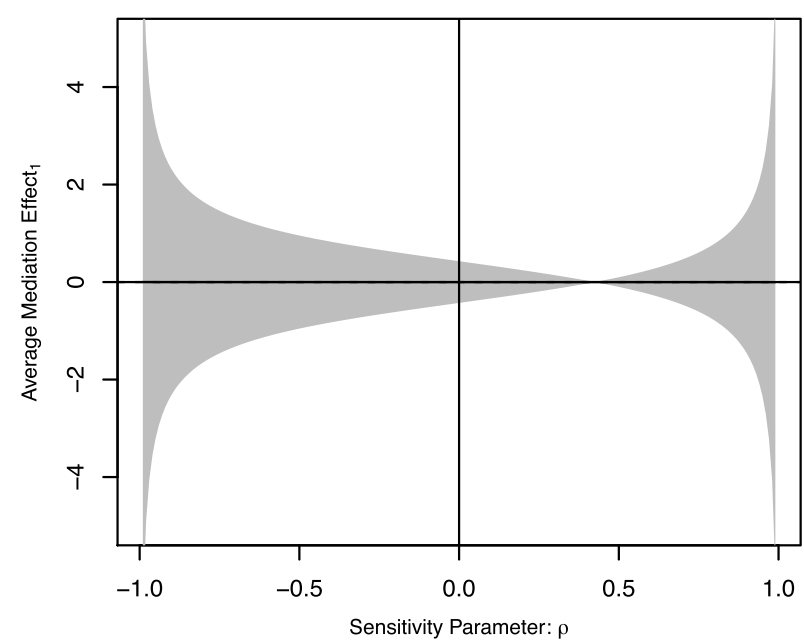




\section{References}

Asghari, A., Nicholas, M., 2009. An investigation of pain self-efficacy beliefs in Iranian chronic pain patients: a preliminary validation of a translated English-language scale. Pain Med. 10, 619-632. https://doi.org/10.1111/j.1526-4637.2009.00623.x.

Baadjou, V., 2017, February 23. Mediation Analysis. Open Science Framework. https:// osf.io/8uk7z.

Brown, T.A., Chorpita, B.F., Korotitsch, W., Barlow, D.H., 1997. Behav. Res. Ther. 35 (1), 79-89.

Cooney, G.M., Dwan, K., Greig, C.A., Lawlor, D.A., Rimer, J., Waugh, F.R., McMurdo, M., Mead, G.E., 2013. Exercise for depression. Cochrane Database Syst. Rev. 9, CD004366. https://doi.org/10.1002/14651858.CD004366.pub6.

Flor, H., Behle, D., Birbaumer, N., 1993. Assessment of pain-related cognitions in chronic pain patients. Behav. Res. Ther. 31 (1) 63-13.

Foster, N.E., Anema, J.R., Cherkin, C., Chou, R., Cohen, S.P., Gross, D.P., Ferreira, P.H., Fritz, J.M., Koes, B.W., Peul, W., Turner, J.A., Maher, C.G., on behalf of the Lancet Low Back Pain Series Working Group, 2018. Prevention and treatment of low back pain: evidence, challenges and promising directions. Lancet 391, 2368-2383. https:// doi.org/10.1016/S0140-6736(18)30489-6.

Hartvigsen, J., Hancock, M.J., Kongsted, A., Louw, Q., Ferreira, M.L., Genevay, S., Hoy, D., Karppinen, J., Pransky, G., Sieper, J., Smeets, R.J., Underwood, M., on behalf of the Lancet Low Back Pain Series Working Group, 2018. What low back pain is and why we need to pay attention. Lancet 391, 2356-2367. https://doi.org/10.1016/ S0140-6736(18)30480- X.

Henschke, N., Maher, C.G., Refshauge, K.M., Herbert, R.D., Cumming, R.G., Bleasel, J., York, J., Das, A., McAuley, J.H., 2008. Prognosis in patients with recent onset low back pain in Australian primary care: inception cohort study. BMJ Jul 7, 337. https:// doi.org/10.1136/bmj.a171. a171.

Hill, J.C., Dunn, K.M., Lewis, M., Mullis, R., Main, C.J., Foster, N.E., Hay, E.M., 2008. A primary care back pain screening tool: identifying patient subgroups for initial treatment. Arthritis Rheum. 59 (5), 632-641. https://doi.org/10.1002/art.23563.

Hoy, D., March, L., Brooks, P., Blyth, F., Woolf, A., Bain, C., Williams, G., Smith, E., Vos, T., Barendregt, J., Murray, C., Burstein, R., Buchbinder, R., 2014. The global burden of low back pain: estimates from the Global Burden of Disease 2010 study. Ann. Rheum. Dis. 73 (6), 968-974. https://doi.org/10.1136/annrheumdis-2013-204428.

Imai, K., Keele, L., Tingley, D., 2010. A general approach to causal mediation analysis. Psychol. Methods 15 (4), 309-334. https://doi.org/10.1037/a0020761.

Lee, H., Lamb, S.E., 2017. Advancing physical therapist interventions by investigating causal mechanisms. Phys. Ther. 97 (12), 1119-1121. https://doi.org/10.1093/ptj/ pzx095.

Lee, H., Mansell, G., McAuley, J.H., Kamper, S.J., Hübscher, M., Moseley, G.L., Wolfenden, L., Hodder, R., Williams, C., 2016. Causal mechanisms in the clinical course and treatment of back pain. Best Pract. Res. Clin. Rheumatol. 30 (6), 1074-1083. https://doi.org/10.1016/j.berh.2017.04.001.

Lovibond, P.F., Lovibond, S.H., 1995. The structure of negative emotional states: comparison of the depression anxiety stress scales (DASS) with the beck depression and anxiety inventories. Behav. Res. Ther. 33 (3), 335-343.

Mansell, G., Hill, J.C., Main, C., Vowles, K.E., van der Windt, D., 2016. Exploring what factors mediate treatment effect: example of the STarT back study high-risk intervention. J. Pain 17 (11), 1237-1245. https://doi.org/10.1016/j.jpain.2016.08.005.

Marin, T.J., Eerd van, D., Irvin, E., Couban, R., Koes, B.W., Malmivaara, A., Tulder van, M.W., Kamper, S.J., 2017. Multidisciplinary biopsychosocial rehabilitation for subacute low back pain. Cochrane Database Syst. Rev. 28 (6), CD002193. https://doi. org/10.1002/14651858.CD002193.pub2.

Miller, R., Kori, S., Todd, D., 1991. The Tampa Scale: a measure of kinisophobia. Clin. J. Pain 7 (1), 51.

Ng, F., Trauer, T., Dodd, S., Callaly, T., Campbell, S., Berk, M., 2007. The validity of the 21-item version of the Depression Anxiety Stress Scales as a routine clinical outcome measure. Acta Neuropsychiatr. 19 (5), 304-310. https://doi.org/10.1111/j.16015215.2007.00217.x.

National Institute for Health and Care Excellence (NICE), 2016. Low Back Pain and Sciatica in over 16s: Assessment and Management. NICE Guideline [NG59]. NICE, London (UK).

Nicholas, M., 2007. The pain self-efficacy questionnaire: taking pain into account. Eur. J. Pain 11, 153-163.

Pengel, L.H., Herbert, R.D., Maher, C.G., Refshauge, K.M., 2003. Acute low back pain: systematic review of its prognosis. BMJ 327 (7410), 323.

Pengel, L.H., Refshauge, K.M., Maher, C.G., Nicholas, M.K., Herbert, R.D., McNair, P., 2007. Physiotherapist-directed exercise, advice, or both for subacute low back pain: a randomized trial. Ann. Intern. Med. 146 (11), 787-796.

Pinheiro, M.B., Ferreira, M.L., Refshauge, K., Maher, C.G., Ordoñana, J.R., Andrade, T.B., 2016. Symptoms of depression as a prognostic factor for low back pain: a systematic review. Spine J. 16, 105-116. https://doi.org/10.1016/j.spinee.2015.10.037.

Qaseem, A., Wilt, T.J., McLean, R.M., et al., Clinical Guidelines Committee of the American College of Physicians, 2017. Non-invasive treatments for acute, subacute, and chronic low back pain: a clinical practice guideline from the American College of Physicians. Ann. Intern. Med. 166, 514-530.

Roland, M., Morris, R., 1983. A study of the natural history of back pain. Part I: development of a reliable and sensitive measure of disability in low-back pain. Spine 8 (2), $141-144$.

Shaw, W.S., Hartvigsen, J., Woiszwillo, M.J., Linton, S.J., Reme, S.E., 2016. Psychological distress in acute low back pain: a review of measurement scales and levels of distress reported in the first 2 months after pain onset. Arch. Phys. Med. Rehabil. 97 (9), 1573-1587. https://doi.org/10.1016/j.apmr.2016.02.004.

Shrier, I., Platt, R.W., 2008. Reducing bias through directed acyclic graphs. BMC Med. Res. Methodol. 8, 70. https://doi.org/10.1186/1471-2288-8-70.

Tingley, D.Y., Hirose, K., Keele, L., Imai, K., 2014. Mediation: R package for causal mediation analysis. J. Stat. Softw. 59 (5), 1-38. https://doi.org/10.18637/jss.v059. i05.

Traeger, A.C., Hübscher, M., Henschke, N., et al., 2015. Effect of primary care-based education on reassurance in patients with acute low back pain: systematic review and meta-analysis. JAMA Intern. Med. 175, 733-743.

Traeger, A., Buchbinder, R., Harris, I., Maher, C., 2017. Diagnosis and management of low-back pain in primary care. CMAJ (Can. Med. Assoc. J.) 13 (189), E1386-E1395. https://doi.org/10.1503/cmaj.170527.

VanderWeele, T., 2015. Explanation in Causal Inference: Methods for Mediation and Interaction. Oxford University Press.

Vlaeyen, J.W., Crombez, G., 1999. Fear of movement/(re)injury, avoidance and pain disability in chronic low back pain patients. Man. Ther. 4 (4), 187-195.

Vlaeyen, J.W., Linton, S.J., 2012. Fear-avoidance model of chronic musculoskeletal pain: 12 years on. Pain 153 (6), 1144-1147. https://doi.org/10.1016/j.pain.2011.12.009. Weermeijer, J.D., Meulders, A., 2018. Clinimetrics: Tampa scale for kinesiophobia. J. Physiother. 64 (2), 126. https://doi.org/10.1016/j.jphys.2018.01.001. 